\title{
EL LENGUAJE INTEGRAL EN EL GRUPO INTERACTIVO II: GUÍA PEDAGÓGICA
}

\author{
Jeanneth Cerdas Núñez \\ Ana Polanco Hernández \\ Patricia Rojas Núñez
}

\author{
Recibido 18-III-2002 • Aceptado 9-IV-2002
}

\section{Introducción}

Resumen: En los últimos años la filosofía del Lenguaje Integral se ha venido promoviendo en diversas instituciones educativas, como una opción para generar procesos de construcción de lenguaje y conocimiento desde una perspectiva constructivista en los salones de clase.

Con base en algunas de las experiencias desarrolladas en nuestro contexto costarricense, surgió la idea de elaborar una guía didáctica que considere algunos elementos de la filosofía del Lenguaje Integral para abordar la práctica pedagógica con niños de edades entre 4 y 5 años. Dicha guía contempla básicamente estrategias para diseñar y operacionalizar el planeamiento didáctico y lineamientos para organizar el ambiente físico del aula.

Para efectos de implementar la guía didáctica elaborada, es necesario que cada usuario profundice en los diferentes aspectos de la filosofía del Lenguaje Integral y de esta manera pueda adecuar la propuesta a su contexto.

En los últimos años la filosofía del Lenguaje Integral se ha venido promoviendo en instituciones educativas de diferentes países del continente americano, se tiene conocimiento de experiencias en Venezuela, Puerto Rico, Perú, Estados Unidos (California), Argentina, entre otros.

En nuestro país ya se han dado algunos acercamientos con el Lenguaje Integral, específicamente se tiene conocimiento de algunas experiencias que se han generado en el Ciclo de Transición y con niños de edades comprendidas entre los 4 y 5 años (grupo de edad que recientemente el Ministerio de Educación a comenzado a denominar Nivel Interactivo II).

Con base en la experiencia desarrollada en los centros educativos de nuestro país, se consideró oportuno elaborar un documento cuyos objetivos principales fueran identificar algunas pautas generales para aplicar lineamientos de la filosofía del Lenguaje Integral y elaborar una guía didáctica que contenga algunos elementos de la filosofía del Lenguaje Integral para abordar la práctica pedagógica con niños de edades entre 4 y 5 años (Grupo Interactivo II), de manera que cualquier docente que desee implementar esta filosofía en su salón de clases cuente con un instrumento de apoyo, para iniciar un proceso integral y de mayor flexibilidad. 
Dicha guía contempla básicamente estrategias para diseñar y operacionalizar el planeamiento didáctico y lineamientos para organizar el ambiente físico del aula.

Este proyecto surgió gracias a la colaboración de un grupo de cinco docentes de educación preescolar que aplicaban la filosofía del Lenguaje Integral con niños de edades entre 4 y 5 años y con los aportes de una especialista en educación preescolar que culminó en el año 2001 un proceso investigativo en un aula del Ciclo de Transición donde se aplicaba dicha filosofía.

Para propiciar el acercamiento con las 5 docentes se utilizó la técnica de grupo focal, según Hernández (s.f.) esta estrategia permite recopilar impresiones de un grupo de personas acerca de una temática preestablecida por el investigador, en este caso la técnica generó un intercambio de opiniones entre las docentes abordando los siguientes aspectos:

- Iniciación y experiencia con el Lenguaje Integral.

- $\quad$ Estrategias para abordar el planeamiento didáctico desde esta filosofía.

- $\quad$ Estrategias para operacionalizar el planeamiento didáctico.

- Lineamientos para organizar el ambiente físico.

- Limitaciones que han enfrentado y recomendaciones.

Para rescatar las apreciaciones de la investigadora se realizó una conversación formal o espontánea donde se abordaron aspectos generales del Lenguaje Integral.

Posterior a este proceso, se generó una segunda etapa de trabajo en el que las participantes, revisaron un avance del trabajo y realizando las observaciones necesarias.

Es importante mencionar, que para efectos de implementar la guía didáctica elaborada, es necesario que cada usuario profundice en los diferentes aspectos de la filosofía del Lenguaje Integral y de esta manera pueda adecuar la propuesta a su contexto educativo.

\section{Marco de referencia teórico}

El Lenguaje Integral es una filosofía que responde a una concepción constructivista del proceso educativo, dicha filosofía se basa en principios científicos y humanistas y está apoyada por áreas del conocimiento en el campo de la lectoescritura, el desarrollo infantil y el desarrollo curricular integrado.

Algunos de los principios que sustentan esta filosofía se derivan de la Nueva Educación de 1980, de la Educación Progresista de los años 20 con John Dewey, y del movimiento de aula abierta de finales de los años sesenta y comienzos de los setentas (Arellano, A., 1993).

En los últimos años sus mayores exponentes han sido Kenneth y Yetta Goodman, investigadores estadounidenses que han realizado estudios acerca del desarrollo temprano y el proceso de escritura, de la inteligencia artificial, del análisis del discurso, de la crítica literaria, de la teoría de los esquemas y del análisis de miscues (inventarios de respuestas inesperadas que producen los lectores mientras leen en forma oral). En América Latina se destacan los trabajos realizados por Adelina Arellano en Venezuela, Daisy Ruiz y Ruth Sáez en Puerto Rico.

Arellano (1993) señala que la filosofía del Lenguaje Integral contempla tanto el aprendizaje del lenguaje como cualquier otro contenido curricular. En este “...la filosofía no es un método para enseñar a leer y escribir sino que es una nueva concepción del lenguaje y ser humano en interacción, donde maestros e infantes tienen un papel protagónico en el proceso de enseñanza y aprendizaje como investigadores 
de contextos socioculturales para conocer la realidad" (Chaves, 1999, p. 45).

El Lenguaje Integral “...se apoya en cuatro pilares humanístico-científicos. Tiene una teoría del aprendizaje, una teoría del lenguaje, una visión básica de la docencia y el rol del docente y un concepto del currículo centrado en el lenguaje" (Goodman, 1989, p. 42).

En cuanto a la teoría del aprendizaje se sostiene que aprender el lenguaje es fácil cuando es integral, real y relevante, cuando tiene sentido y es funcional. Así mismo, se señala que el lenguaje es tanto personal como social y se aprende a medida que el sujeto lo utiliza para aprender.

Respecto de la teoría del lenguaje, se parte de darle valor a todas las lenguas y dialectos, pues se considera que cada forma de lenguaje constituye un recurso lingüístico valioso para sus usuarios, por lo tanto, lo que se pretende es que el Lenguaje Integral sea realmente integral.

En relación con la visión de la enseñanza y el rol del docente se plantea que el respeto y la comprensión del aprendizaje y del lenguaje son equivalentes al respeto y la comprensión en la enseñanza. Se apunta que los docentes que aplican la filosofía del Lenguaje Integral entienden que el aprendizaje es un proceso que se desarrolla en los niños uno a uno, y que su función consiste en crear ambientes e interacciones sociales apropiadas, e influir en la velocidad y dirección de aprendizaje personal, dando guía y apoyo, monitorizando, alentando y facilitando el aprendizaje, pero sin controlarlo.

Por último, en cuanto a la visión del currículo, se sostiene que si el lenguaje se aprende mejor cuando es integral y en un contexto natural, entonces la integración es un principio fundamental para el desarrollo lingüístico y el aprendizaje a través del lenguaje.

\section{Pautas generales para aplicar lineamientos de la filosofía del Lenguaje Integral en la práctica pedagógica con niños del Grupo Interactivo II}

\section{El planeamiento didáctico desde la perspectiva del Lenguaje Integral}

La filosofía del Lenguaje Integral permite la incorporación de experiencias de aprendizaje de los niños en relación con su contexto sociocultural y escolar, de esta manera se evita la fragmentación del conocimiento en áreas académicas visualizando la enseñanza como una totalidad.

Para que esta integración sea pertinente, es importante que el currículo que se desarrolle sea construido bajo un proceso de colaboración entre docentes y estudiantes. Desde esta perspectiva, se requiere tomar en cuenta al educador en su capacidad para tomar decisiones en su salón de clases, su experiencia profesional y su conocimiento acerca del proceso de enseñanza aprendizaje, de igual manera, valorar la participación del alumno, como miembro de un grupo familiar, que posee un conocimiento previo.

Edelsky, C;. Altwerger, B; y Flores, B; (1991), citados por Sáez, R.; López, L.; y Santiago, L. (1995) señalan que existen varios modelos de integración curricular: la unidad temática en la cual se selecciona un tema y se planifica la integración de las disciplinas académicas en relación con este y, el ciclo temático que se refiere al estudio de un tema, el cual a su vez puede conducir al estudio de otro sin que exista un corte abrupto. De esta manera, dependiendo del interés de los niños y del docente, puede encontrarse en los salones de clase unidades temáticas en algunos momentos y en otros, ciclos temáticos; sin embargo, los autores señalan que este último está más acorde con los planteamientos del Lenguaje Integral. 


\section{Pasos para la elaboración del planeamiento}

La experiencia con Lenguaje Integral ha llevado a poner en práctica un proceso de planificación en el cual participa tanto el docente como el alumno. Esta actividad permite activar el conocimiento previo de los niños, tomar en cuenta sus necesidades e intereses, y establecer relaciones entre las diversas áreas que componen el proceso educativo. Además permite incorporar el aporte profesional del docente o docentes en relación con el tema propuesto, este proceso de planificación se realiza por medio de una negociación entre docente y alumnos. Se sugiere abordarlo considerando las siguientes etapas:

\section{Selección del tema}

La planificación se inicia seleccionando un tema, el cual puede ser escogido por los niños utilizando diversos medios según la creatividad del docente. Como resultado de esta selección se escoge un tópico para desarrollar la unidad temática o ciclo temático.

Para motivar al niño a expresar qué es lo que desea aprender en el Jardín de Infantes, y levantar un listado de temas se puede recurrir a diferentes estrategias. Inicialmente este proceso es lento, requiere bastante guía del docente para orientar a los niños y que ellos logren ubicar sus intereses; no obstante conforme avanza el año escolar, los niños van interiorizando la dinámica y dicho proceso se agiliza cada vez más. Algunas sugerencias que podrían considerarse para seleccionar el tema son las siguientes:

- Por medio de la observación de los dos primeros meses en que los niños se han incorporado al proceso educativo, el docente puede detectar aquellos elementos o situaciones que les interesan, a partir de esta observación plantearles dos temas sobre los cuales elegir (E. Salazar, comunicación personal, marzo 17, 2000).

- Disponer de juegos, revistas y láminas acordes con la edad de los niños para que ellos los manipulen, y determinar por medio de la observación el aspecto o los aspectos hacia los cuales enfocan su interés, y a partir de esto motivar la escogencia de un tema.

- Solicitar a los niños que lleven de sus hogares un juguete, un dibujo, un recorte de revista de lo que les gustaría aprender en la institución, en este proceso se involucra al padre de familia al colaborar en la búsqueda con el niño. Posteriormente, con ayuda de los niños, se agrupan los materiales por afinidad y el docente realiza un listado de todos los temas aportados por los niños, también pueden seleccionarse los temas de mayor interés y así empezar a filtrar el listado, reduciendo la cantidad para la elección final.

- Realizar una o varias excursiones de manera que el niño tenga la posibilidad de vivenciar diversas situaciones y a partir de esto invitarlos a seleccionar un tema de estudio (M. Picado, comunicación personal, marzo 17, 2000).

- Cuando los niños han interiorizado el proceso de selección de un tema ellos mismos pueden sugerir verbalmente qué les gustaría aprender y el docente anota las opciones en una pizarra o en un cartel, para proceder a realizar la elección.

En el caso de los niños con edades entre 4 y 5 años se recomienda para cualquiera de las opciones descritas anteriormente que el listado de temas no sea superior a cuatro tópicos, además se sugiere escribirlos en un cartel grande con letra legible e ilustrar cada uno para que los niños puedan identificarlos. La docente puede 
elegir el momento de la rutina de trabajo que ella considere más apropiado para realizar esta proposición de temas, sin embargo, uno de los períodos que comúnmente se usa es el de conversación. Es importante señalar que el primer día el proceso de planeamiento debe limitarse únicamente a esta proposición de temas, principalmente en los primeros meses en que se está implementando esta dinámica.

Al día siguiente se puede realizar la selección del tema de estudio por medio de un proceso de votación, explicándole a los niños con claridad las consecuencias de esta dinámica. Se recomienda variar la modalidad de votación de un tema a otro para evitar que el niño desarrolle desinterés por el proceso. Algunas alternativas de selección pueden ser las siguientes:
- Anotar cada tema propuesto en un papelito (lo puede hacer el niño o la docente) y colocar todos los papeles en una caja, para sacar a la suerte el tema que será desarrollado por todos.

- Colocar el cartel con el listado de temas a la altura de los niños para que estos pasen de uno en uno y coloquen una rayita con marcadores o crayolas, en el tema de interés (ver ejemplo). Esta actividad se puede modificar colocando la huellita del niño, una calcomanía, un pedacito de papel, o un dibujo del tema, entre otros (C. Coto, M. Picado, D. Marchena, H. Amador, E. Salazar, comunicación personal, Marzo 17, 2000).

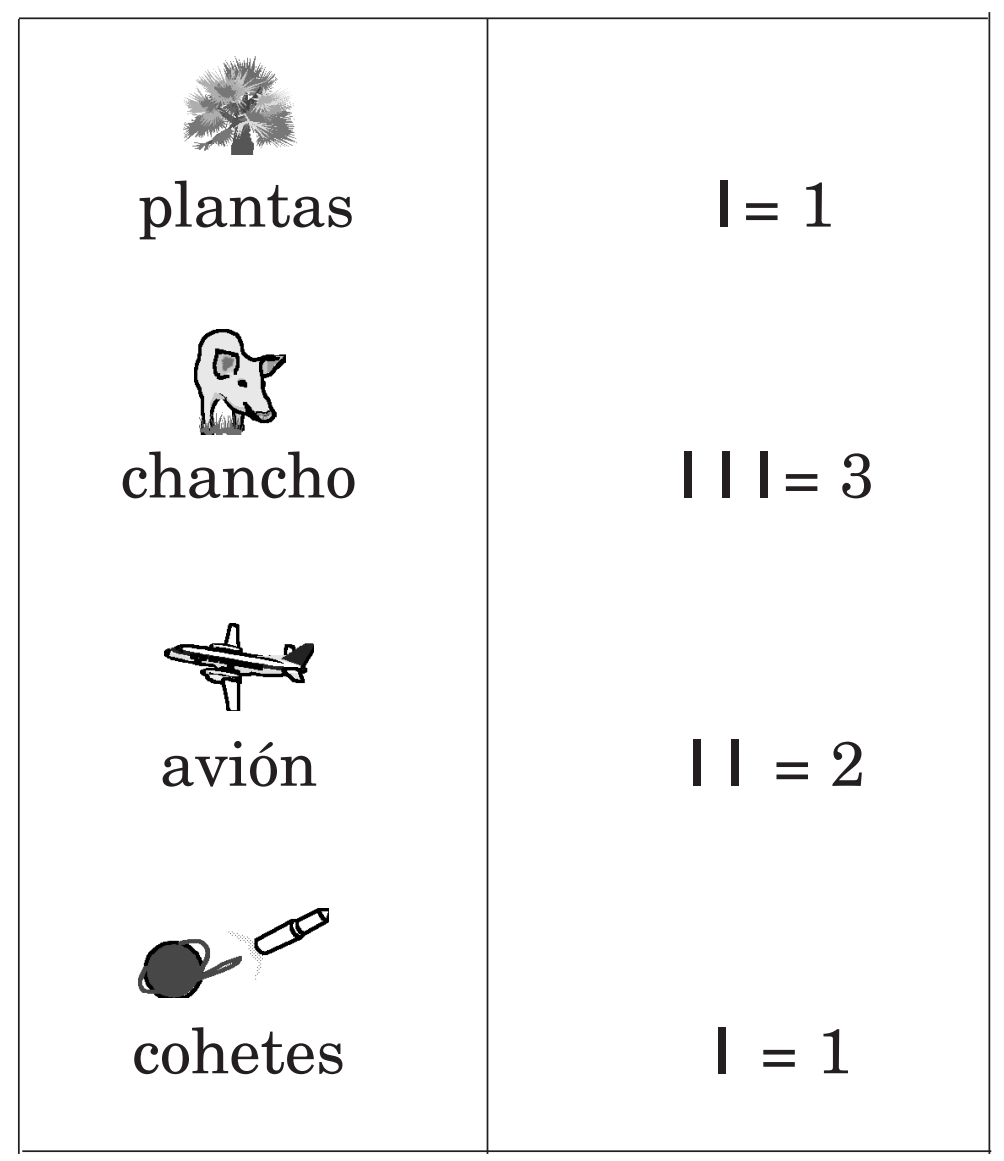


- Una variación de la estrategia anterior es escribir cada tema de un color diferente, y proporcionarles a los niños paletas en una canasta o recipiente grande con los mismos colores de los temas, para que estos elijan la paleta del color del tema que les interesa, y la peguen en el espacio correspondiente.

- Dar a cada niño un papelito en el que dibuje o escriba el tema de su predilección, estos papelitos se pueden colocar en un frasco y se irán abriendo poco a poco hasta tener la contabilidad total de los mismos. Es importante realizar el conteo de votos con los niños y anotar en la pizarra o en un cartel los resultados, de manera que el niño pueda visualizar mejor la contabilidad. Tanto en el caso de los niños que escriben el tema como en el caso de los que lo dibujan, la docente debe preguntarle a cada uno cuál fue el tema que escogió, y anotarlo con escritura convencional previo a la colocación del papelito en el frasco para poder identificar cada elección.

- Votar como se hace en una elección presidencial presentándole al niño una papeleta con el dibujo de los temas propuestos para que él imprima su huella digital en la opción de mayor interés, depositando su papeleta en un buzón. Por último se hace el conteo con todo el grupo, y se anota el puntaje de cada tema en un cartel para descubrir el elegido por la mayoría. Un ejemplo de la presentación de la papeleta puede ser el siguiente:

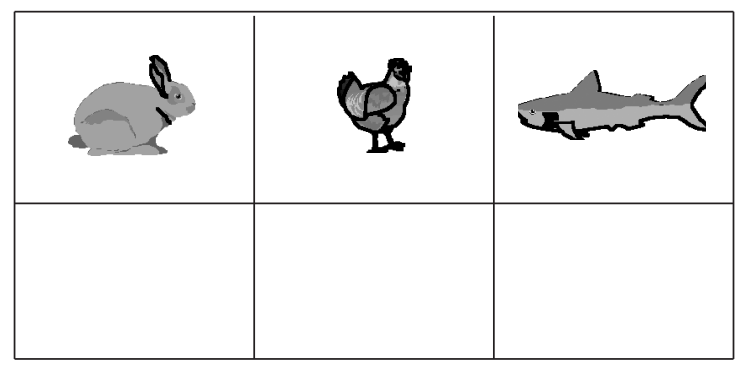

- Escoger un tópico en grupos, de manera que surjan 4 ó 5 temas. Cada uno de los grupos tendrá un tiempo o fecha específica para promocionar su propuesta, al final de la semana se realizará una votación para identificar el tema que haya generado mayor interés. Dicha votación puede realizarse aplicando cualquiera de las alternativas descritas anteriormente (M. Picado, comunicación personal, Marzo 17, 2000).

$\mathrm{Al}$ igual que en el caso de la proposición de temas, este proceso es lento, por lo que se recomienda iniciar con estrategias simples; las que paulatinamente pueden aumentar su complejidad.

Es importante aclarar que en algunos casos puede que no se realice este proceso de selección de tema por las siguientes circunstancias:

- $\quad$ El interés de los niños puede derivarse del tema anterior (ciclo temático), en este caso lo único que se requiere es confirmar con el grupo si están de acuerdo en trabajar el tema que se originó del anterior estudio.

- En otras ocasiones, por la estructuración del currículo costarricense se requiere abordar temáticas específicas en momentos particulares, que impiden la selección de un tema, por ejemplo, la celebración de la Independencia.

- También pueden encontrarse situaciones en las que el centro infantil desea abordar un tópico a nivel institucional.

- En todos estos casos en que ya existe un tema se puede participar a los niños preguntándoles qué desean aprender de esa temática. 


\section{Exploración del tema}

Luego de seleccionar el tema, se inicia lo que Sáez, R., López, L. y Santiago, L. (1995), llaman preplanificación, que consiste en trabajar con los niños en los tres días siguientes de la selección del tema con tres preguntas generadoras en el siguiente orden: qué sabemos del tema por estudiar; qué queremos aprender del tema, y cómo lo podemos estudiar. Estas preguntas y las respuestas respectivas con los aportes que den los niños se incorporan al planeamiento escrito del docente, generalmente estas preguntas se ubican en la primera página del plan, por ejemplo:

Planeamiento

Tiempo probable: del 19 de julio al 6 de agosto de 1999

Tema de estudio

Las mariposas

¿Qué sabemos?* ¿Qué queremos aprender?*

¿Cómo lo podemos estudiar?

- Las mariposas pueden volar.

- Tienen alas para volar.

- Los gusanos tienen un capullito y se rompe.

- Ponen huevillos.

- Tienen patitas para caminar.

- Se casan.

- Comen.

- Tienen carate.

- Tienen hijos.

- Tienen antenas y en las puntitas rueditas.

- Tienen manchas, algunas en forma de ojos.

- Son de colores.

- Tienen boca
- ¿Cómo comen?

- ¿Cómo vuelan?

- ¿Cómo orinan y echan caquilla?

- ¿Cómo caminan?

- ¿Cómo nacen?

- ¿De qué tamaño son las antenas?

- ¿Cómo le nacen las patitas?

- ¿Tienen las mariposas orejas, dientes, nariz?

- ¿Cómo son las mariposas por dentro?

- ¿Cómo le nacen las alas?
- Confeccionando mariposas.

- Con libros.

- Realizando conferencias.

- Viendo revistas

- Realizando un mariposario.

- Hacer libros de mariposas.

P. Rojas (1999).

*Se recomienda escribir las frases o preguntas tal y como las plantean los niños. 
Para trabajar estas preguntas con los niños el docente debe tratar de guiar la conversación e ir anotando en un cartel o pizarra lo que ellos expresan, enfatizando que en la primera columna se anota todo lo que saben acerca del tema. Una alternativa para ayudarle a los niños a visualizar la diferencia entre lo que saben y desean aprender puede ser utilizar diferentes colores de tizas o marcadores a la hora de escribir (en caso de usar una pizarra el docente debe transcribir la información a un cartel).

En relación con la primera pregunta (¿qué sabemos del tema?) lo que se pretende es identificar el conocimiento previo que poseen los niños acerca de este. Para esto se pueden hacer preguntas, por ejemplo, si se está estudiando el tema de las mariposas, se pueden plantear subpreguntas como las siguientes:

- ¿Cómo son las mariposas?

- ¿Cómo nacen las mariposas?

- ¿Qué comen las mariposas?

- ¿Dónde viven las mariposas?

Es importante señalar que todas las afirmaciones de los niños deben anotarse, aunque estas sean equivocadas, pues durante el desarrollo del tema, el niño tendrá la oportunidad de replantear sus hipótesis.

Cuando se trabaja la segunda pregunta (¿qué queremos aprender?), se recomienda recordar la información escrita en el cartel del día anterior y enfatizarle a los niños que se va a anotar aquello que ellos desean conocer o qué no saben de ese tema y les gustaría aprender. Este día se les puede asignar como tarea, que con la ayuda de su familia busquen en sus hogares libros, fotos, láminas o cualquier otro material que se pueda llevar a la clase al día siguiente. Este material sirve de motivación para trabajar la tercera pregunta.

El tercer día se trabaja la última pregunta (¿cómo podemos estudiarlo?) de manera que los niños sugieran qué les gustaría hacer, qué material les gustaría llevar al aula o qué les gustaría que el docente lleve al salón de clases acerca del tema.

Toda la información que se genera entre el docente y sus alumnos se puede construir en un periodo de conversación o de interacción docente-niños, es aquí donde la transacción adulto-niño juega un papel importante y se le da pertinencia al proceso, al adecuarse el estudio del tema a los intereses y necesidades del alumno, y a la realidad de su entorno.

Es recomendable, por la edad de los niños, que el abordaje de las tres preguntas generadoras se realice progresivamente de un proceso de planeamiento a otro, es decir, en el primer plan que se genere por medio de esta dinámica, plantearle a los niños únicamente la primer pregunta, en el segundo planeamiento las dos primeras preguntas y a partir del tercero las tres preguntas. No obstante este proceso puede variar de un grupo a otro dependiendo de las características del mismo, en algunos casos pueden ser suficientes tres planeamientos, pero en otros se puede extender.

\section{Organización del tema}

La información obtenida con las tres preguntas generadoras, es retomada posteriormente por el docente en un mapa semántico. Este mapa semántico “...es un instrumento de aprendizaje que se construye en un dispositivo y organizador gráfico de la información, que muestra las principales categorías de análisis acerca del tema de estudio" (Arguedas, 1995, p. 67). Además se convierte en “...un método para representar gráfica y visualmente relaciones entre ideas y conceptos enfatizando los procesos mentales cognitivos más altos y promoviendo o estimulando la solución de problemas" (Mcneil (1987) citado por Brunet, 1995, p. 319).

Este mapa parte de un proceso dinámico en el que se toman en cuenta los conocimientos previos de los alumnos, para 
integrar luego los aspectos curriculares que el docente considere pertinente desarrollar a la luz del tema seleccionado, y lograr así la estructuración del conocimiento y la integración de nuevos conceptos.

El mapa semántico para la planificación puede establecerse a partir de las tres áreas del desarrollo (socioemocional, cognitivo-lingüística y psicomotriz) o puede desarrollarse en disciplinas tomando como básicas las siguientes: matemática, lenguaje, investigación social, investigación científica, música, arte, y educación física; también puede desglozarse el área de lenguaje en lectura, escritura, escucha y drama (Sáez, R., López, L. y Santiago, L.,
1995). Aquí el docente incorpora lo que el niño quiere aprender y la manera como lo quiere investigar (información recopilada en la pregunta 2 y 3 del proceso de preplanificación), clasificando la información en cada una de las disciplinas para ofrecerle al niño un ambiente integral e incorporando los aspectos curriculares que él considere pertinentes, de acuerdo con la propuesta programática que está utilizando.

A continuación se presenta gráficamente el mapa semántico por áreas de desarrollo y el mapa semántico por disciplinas académicas y se ilustra con un ejemplo este último.

- $\quad$ Por áreas del desarrollo

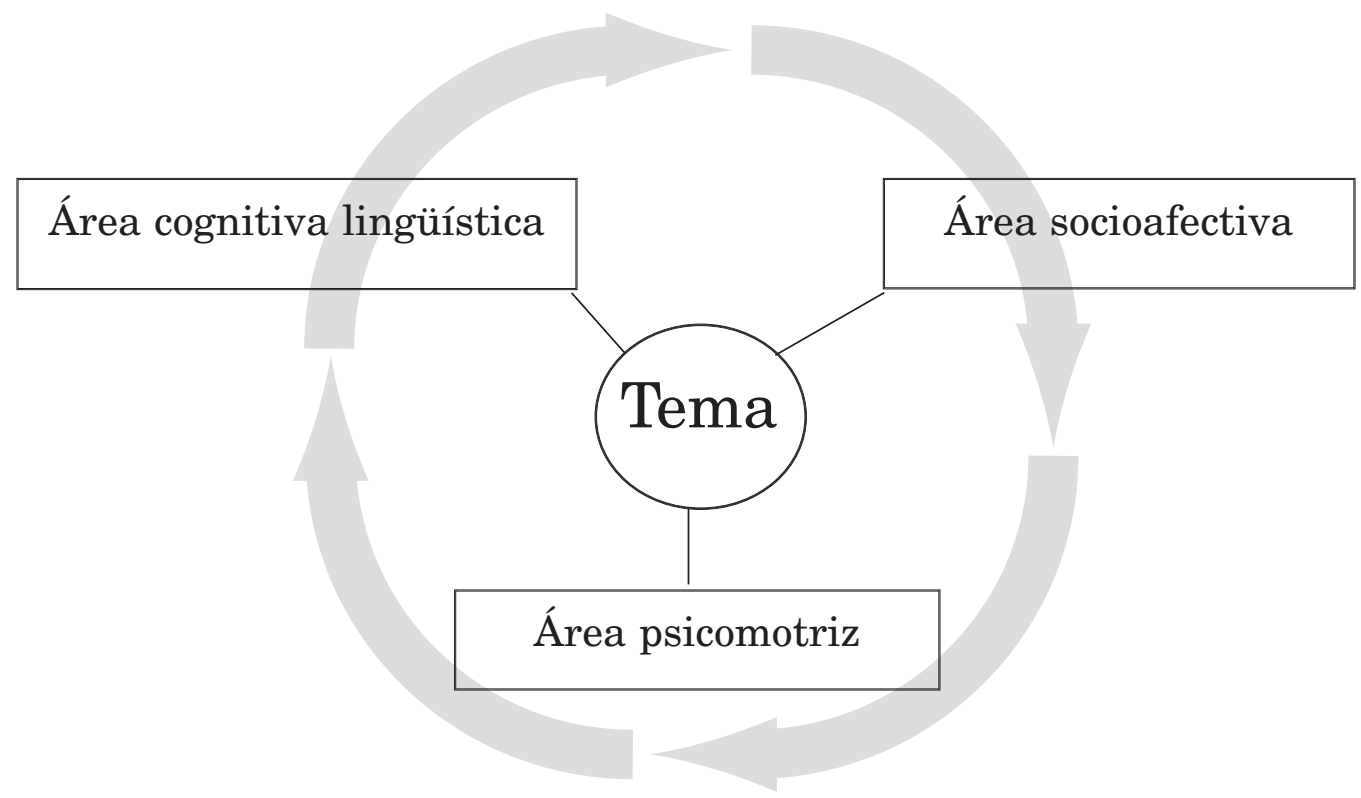


- $\quad$ Por disciplinas académicas

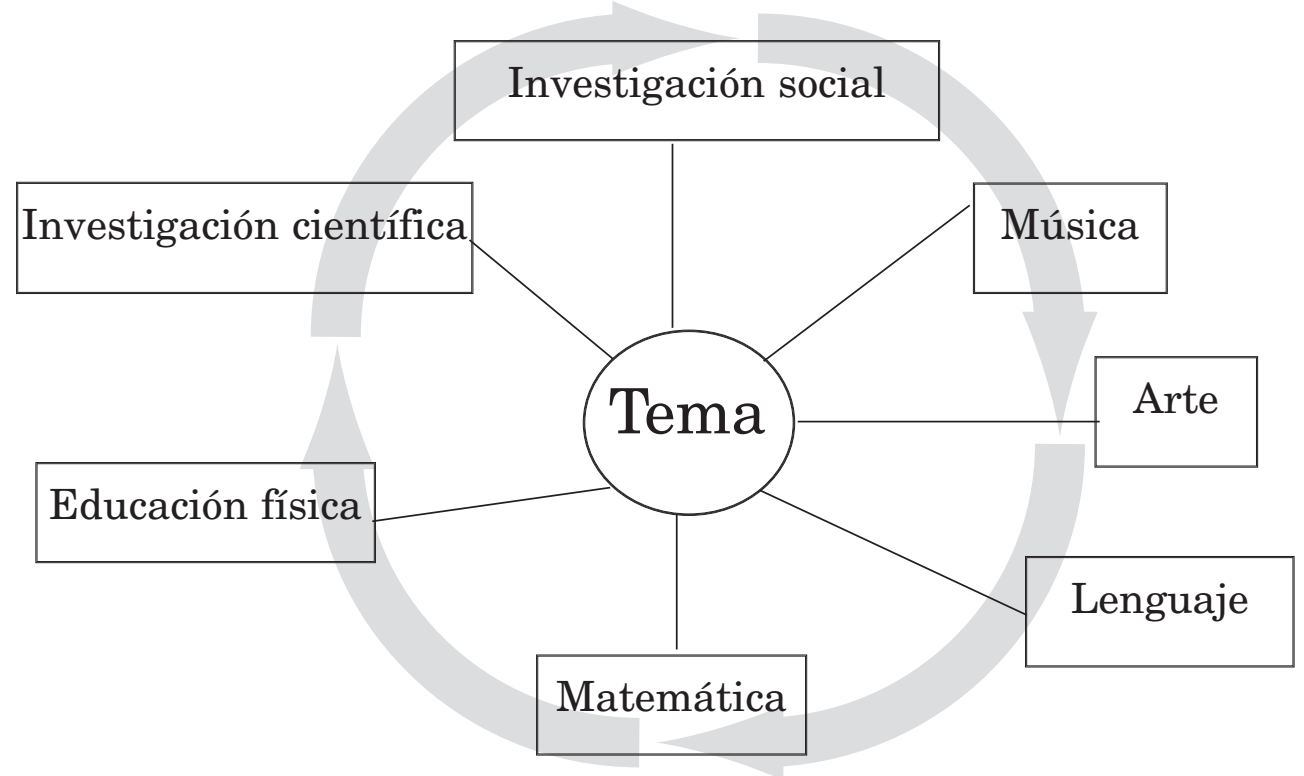

- $\quad$ Ejemplo por disciplinas académicas del tema de las mariposas

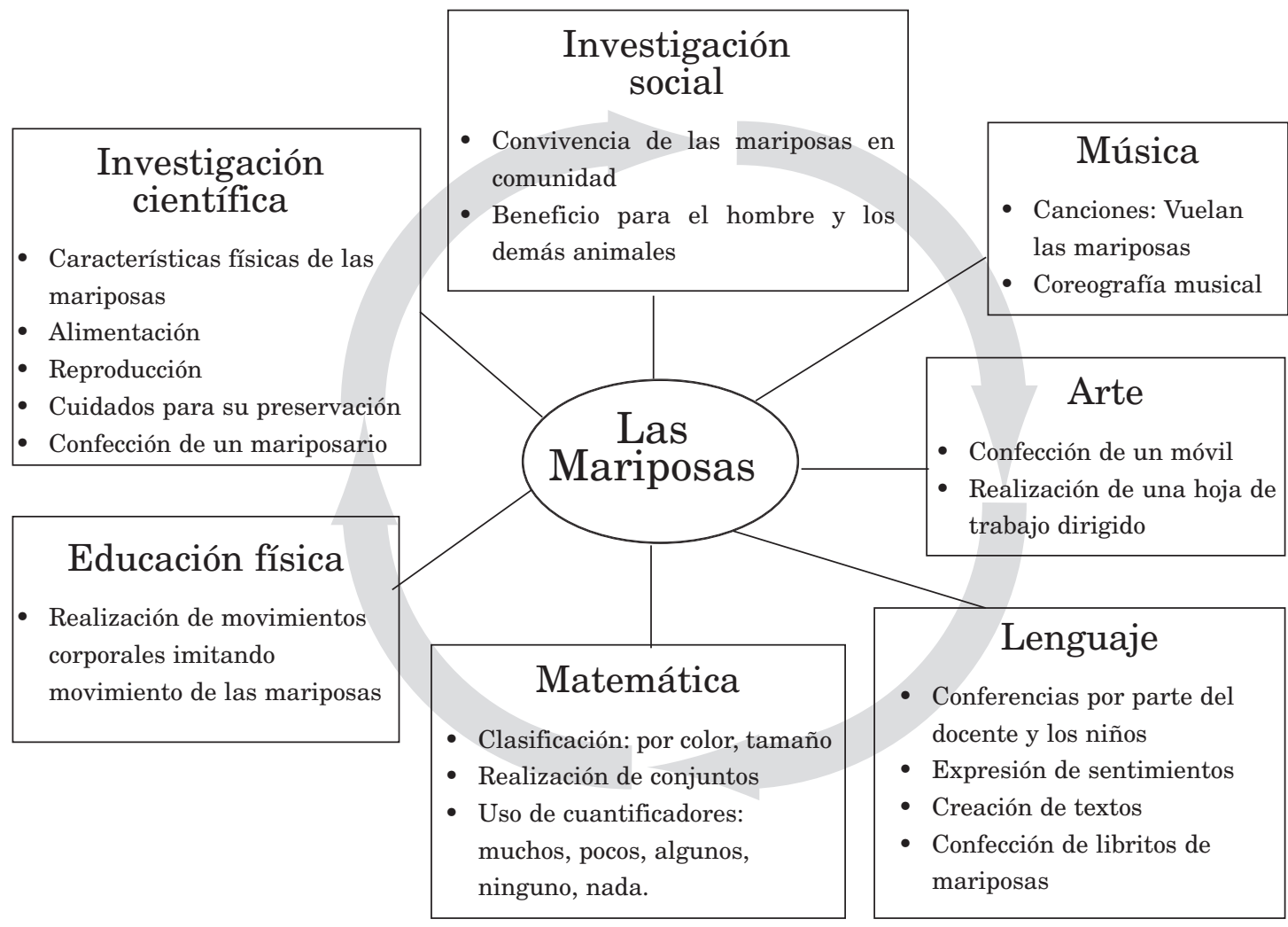




\section{Programación}

Después de realizar el mapa semántico, en el cual lo que se establece es una lluvia de ideas para visualizar la integración de contenidos, el docente está listo para realizar su planeamiento contemplando los lineamientos curriculares que el programa de estudio o la institución proponen. Se recomienda que el planeamiento tenga un tiempo probable de operacionalización de dos semanas; sin embargo, este plan puede durar un poco más de tiempo según el interés que los niños mantengan. Cuando el planeamiento se extienda más de tres semanas, es conveniente retomar en una sesión general el tema con el grupo, y analizar los avances y los intereses aún existentes, con el único propósito de mantener el entusiasmo de los niños o de iniciar nuevamente otra elección.

Es importante aclarar que la programación es solo una guía y aunque se prevee un tiempo para su desarrollo y unas estrategias determinadas para su operacionalización, está sujeta a la dinámica que se genere en el aula con los alumnos, por lo tanto, puede requerir ajustes.

\section{Operacionalización del planeamiento didáctico desde la perspectiva del Lenguaje Integral}

En un ambiente en el cual se implementa la filosofía del Lenguaje Integral el aprendizaje se concibe como algo activo, dinámico, donde la interacción entre el adulto y el niño o entre los mismos niños resulta muy importante para la conquista del conocimiento; ya que son ellos quienes construyen, modifican, enriquecen y diversifican constantemente sus esquemas, para atribuirle sentido a los contenidos y aprenderlos (Coll, C. y otros, 1997; Carretero, M., 1997). Por esta razón, el aprendizaje se vuelve transaccional, ya que se da constantemente un intercambio de ideas, sentimientos, descubrimientos, reflexiones en torno a lo que sucede a su alrededor o a lo que se estudia en el momento; es decir, se produce un aprendizaje significativo, un aprendizaje que tiene sentido e interés para el estudiante.

Para que un aprendizaje de tal magnitud pueda lograrse en un salón de clases se necesita hacer algunos ajustes que posibiliten el ambiente de trabajo del niño y los adultos hacia metas más interactivas, particularmente en lo que respecta a la puesta en práctica del planeamiento, pueden considerarse las siguientes estrategias:

- Complementar la unidad temática o ciclo temático desarrollada en el aula con los niños con la visita de especialistas que lleguen a contarles o explicarles algún tópico específico. Una variante de esta actividad puede ser realizar con los mismos padres del grupo talleres con los niños o sesiones demostrativas del tema a desarrollar. Otra alternativa que se sugiere puede ser la visita del grupo al lugar de trabajo de esta persona o estas personas.

- Realizar excursiones que ilustren el tema desarrollado con los niños, de manera que estos tengan la oportunidad de experimentar vivencias concretas.

- Incorporar en la mayoría de actividades la escritura tanto a nivel convencional por parte del docente, como no convencional por parte de los niños, por ejemplo, en carteles, en la confección de libros hechos por los niños individual o grupalmente.

- Alternar el trabajo en el aula con espacios para el trabajo individual y grupal.

- Participar al niño en el aporte de material ya sea confeccionado por estos mismos o traído desde su hogar.

- Utilizar una agenda grupal (cartel de rutina diaria) para organizar el trabajo diario, donde los mismos niños al iniciar la mañana, escriban e ilustren con ayuda del docente el orden 
de las actividades que van a realizar durante el día (M. Picado, conversación personal, Marzo 17, 2000).

- Complementar el tema de estudio que se desarrolla con los niños, incorporando a las áreas de trabajo materiales relacionados con el mismo.

- La reflexión, la criticidad y la imaginación son muy valiosas dentro de esta filosofía, por lo tanto, la creación de textos, canciones, poesías por parte de los niños tanto a nivel individual como grupal, pueden ser muy valiosos en el proceso de aprendizaje.

- Cuando se trabaja con niños de edades entre los 4 y 5 años es importante presentar las experiencias lo más concretas posible y tratar de "llevar el tema al aula”, por ejemplo, si se está estudiando el conejo, sería muy apropiado llevar un conejo al aula, favoreciendo de esta manera no sólo la construcción de conocimiento, sino, la sensibilización de los niños y la puesta en práctica de normas para poder tener un ser vivo en el aula (D. Marchena, conversación personal, Marzo 17, 2000).

Partiendo de los ejemplos anteriores, es importante señalar que, dentro de esta visión integral, el alumno se considera un participante activo, él es el actor y ejecutor principal de las actividades. Con esta concepción tiene el poder de escoger y expresar sus ideas en relación con los contenidos curriculares, es el alumno quien explora, construye interrogantes, las discute y analiza las alternativas para lograr una respuesta a sus inquietudes.

Por su parte, el docente debe participar en la creación de situaciones de aprendizaje donde el alumno pueda obtener los instrumentos necesarios para la construcción del conocimiento. El educador se concibe como guía y promotor de experiencias, respeta los aprendizajes previos de sus alumnos y adecua el proceso a cada uno de ellos para colaborar en la resolución de sus problemas.
Debe desarrollar cualidades para observar y buscar el momento oportuno de intervenir con sus estudiantes, debe ayudar a los niños más lentos y estimular a aquellos que siempre quieren aprender más. Debe comprender que la evaluación no es el resultado de la suma de conocimientos, sino un proceso activo que logra el estudiante, más que un resultado.

Desde esta perspectiva, el docente debe ser una persona que guste trabajar con los niños, que ofrezca un proceso educativo capaz de favorecer el potencial afectivo, espiritual, motriz y cognitivo de sus alumnos. Debe ser una persona a la que le guste su trabajo y que esté constantemente buscando alternativas para su enriquecimiento profesional.

Dentro de este proceso de interacción, el padre de familia se convierte en un elemento valioso para enriquecer y apoyar el proceso educativo, los padres y demás parientes de los niños pueden colaborar brindando su ayuda, constituyéndose así en voluntarios que apoyan al docente en la labor de aula. En aquellos casos en que el padre de familia no puede estar presente en el aula, puede brindar su colaboración desde su hogar enviando materiales, buscando amigos o especialistas que ilustren los contenidos escolares o buscando artículos en Internet $\mathrm{u}$ otros medios de comunicación. Es de gran ayuda abrir las puertas a los padres, miembros de la comunidad y estudiantes que deseen hacer acción social en las clases de los niños, de manera que en conjunto docentes, niños, familia y comunidad, se unan por una causa común: favorecer el crecimiento integral de todos.

\section{Organización del ambiente físico desde la perspectiva del Lenguaje Integral}

\section{Disposición del espacio físico}

El ambiente que se genera en un salón de clase es un factor importante por 
considerar, puesto que este es el sitio en el que se llevan a cabo la mayoría de las actividades que se realizan durante una jornada diaria, por ello es fundamental que reúna las condiciones necesarias que favorezcan el desarrollo integral del educando.

Desde la posición de la filosofía del Lenguaje Integral, el espacio físico se puede dividir en áreas de trabajo donde se incorporan materiales y experiencias que le permiten al niño acercarse a la lectoescritura de manera natural. Algunas de las áreas de trabajo que comúnmente se construyen con niños de edades entre 4 y 5 años son las conocidas bajo la siguiente denominación: dramatización, construcción, juegos tranquilos, artes plásticas y el centro de lenguaje.

De acuerdo con el Programa de estudios propuesto por el Ministerio de Educación Pública para el Ciclo Materno Infantil, dichas áreas de trabajo estarían representadas por los espacios de interacción que se sugieren. En este sentido, es importante señalar que independientemente de la manera como se les denomine a estos espacios, lo importante para la filosofía del Lenguaje Integral es que en cada uno de ellos se favorezca el acercamiento natural y espontáneo del niño con la lectoescritura.

\section{Decoración del espacio físico}

Con respecto a la decoración del aula L. Chaves (Comunicación personal, marzo 24, 2000) señala que desde la perspectiva del Lenguaje Integral es fundamental que haya un ambiente letrado. Para generar este ambiente se pueden rotular las áreas de trabajo, también los materiales que se encuentran en ellas pueden ser rotulados poco a poco, así como otros objetos del aula de acuerdo con el interés de los niños. Además pueden elaborarse carteles como por ejemplo el de las reglas del grupo, o de poesías y canciones que los niños conocen. Este trabajo de rotulación y escritura lo puede hacer la docente con letra convencional o los niños escribiendo a su manera.
También pueden combinarse ambas estrategias, y desde luego por la edad de los niños puede acompañarse la escritura con el dibujo o ilustración.

Con todo este material, además de los trabajos que los niños realizan en clase o en el hogar, se decoran las paredes, pegándolo a su altura y variándolo de acuerdo con el tema en estudio y sus intereses. En este sentido, M. Picado (conversación personal, Marzo 17, 2000) señala que es importante darle la oportunidad a los niños de que ellos decoren el aula construyendo un ambiente con el tema que eligieron trabajar.

\section{Materiales y recursos}

Los materiales y recursos que posee un aula que atiende niños de 4 a 5 años en la filosofía del Lenguaje Integral deben invitarlos a elegir, explorar, experimentar, clasificar, probar, compartir, interactuar, leer y escribir, así como también favorecer la independencia, la autonomía, la responsabilidad, el autocontrol, la cooperación, la concentración, el trabajo en equipo y la organización.

Por lo tanto, además de tener diferentes materiales adecuados al interés y edad de los niños, se recomienda proporcionar material que permita su expresión gráfica. Por ejemplo, M. Picado (conversación grupal, marzo 17, 2000) sugiere que en todas las áreas de juego se coloque papel y lápiz, pues de esta manera en dramatización podrían usarlos para hacer la lista de las compras, en científica para escribir el nombre del insecto que cazaron y en construcción para indicar que nadie toque la torre.

Específicamente el centro de lenguaje, que es fundamental para la filosofía del Lenguaje Integral, debe ser un sitio placentero para los niños, permitir la interacción entre ellos y la utilización libre de los materiales que allí se encuentran. Puede poseer una alfombra y almohadones que posibiliten la comodidad para leer, también es necesaria una mesita con sillas para escribir en pizarritas, en carteles, y libros que confeccionen. 
Otros materiales que pueden colocarse son los nombres de los niños del grupo, etiquetas en español de productos alimenticios familiares para ellos, palabras alusivas al tema que están estudiando, palabras que deseen conocer, moldes de letras, letras de diferentes texturas y tamaños, pizarras, tizas, borrador, crayolas, lápices de color, lápices de grafito triangulares (para que el niño adquiera la destreza de coger adecuadamente el lápiz), hojas blancas de distintos tamaños, colores y texturas; papel construcción, cromos, papel de regalo, calcomanías, materiales impresos para recortar, sobres para cartas, buzón, tijeras (para zurdos y derechos), goma y engrapadora. También pueden ubicarse aquí libros de cuentos, de poesía, revistas, panfletos, directorios, periódicos, material impreso sobre el tema que se esté tratando, y todo aquel material gráfico que los niños deseen aportar.

Además pueden complementarse estos materiales con otros como grabadora, cassettes, máquina de escribir, teléfono, teclado de computadora, y si es posible una computadora equipada; pues tal y como lo señala Amador, H. (2000), estos implementos le permiten al niño acercarse a los diferentes medios tecnológicos que utilizan las personas para comunicarse.

También es útil tener una pizarra que pueda colocarse frente al espacio donde se realiza la reunión grupal, ya que brinda la posibilidad de escribir la fecha, poesías y canciones para elegir, decir o cantar, los nombres de los compañeros ausentes, propuestas para una actividad, entre otros, de manera que el leer y escribir se constituyan en parte de la cotidianeidad del aula.

Es importante clarificar que los materiales deben incorporarse poco a poco, considerando la posibilidad de rotarlos o sustituirlos de acuerdo con las necesidades e intereses del niño.

Por último, también resulta oportuno señalar que si bien es cierto en un salón de clase de niños preescolares los materiales son un recurso necesario, nunca sustituyen la labor que debe realizar el docente.

\section{Conclusiones}

Es importante señalar que la guía pedagógica propuesta, es solo eso, "una guía", por lo tanto para efectos de implementarla cada usuario debe profundizar en los diferentes aspectos de la filosofía del Lenguaje Integral, con el fin de apropiarse de sus principios y a partir de esto generar una práctica consciente. Es importante señalar que la guía elaborada, constituye únicamente una propuesta a nivel teórico, pues “...el proceso innovador no concluye hasta que no se consolida el cambio" (De la Torre, 1998, p. 23).

De esta manera la guía no constituye un cambio en sí misma, sino que este se producirá si el docente se da espacio para reflexionar acerca de la manera en que ha venido abordando su labor profesional, pues “...las ideas y concepciones no están en los problemas, ni en los proyectos, sino en las personas" (De la Torre, 1998, p. 21).

En relación con lo anterior, en algunos casos para adoptar las sugerencias que se proponen en la guía, es posible que se requiera un cambio paradigmático, dado que la filosofía del Lenguaje Integral constituye una visión no tradicional del proceso educativo. Este cambio de paradigma no solo tendrá incidencia en la concepción del proceso educativo, sino que posiblemente también transforme el sistema de creencias de cada docente.

\section{Referencias bibliográficas}

Amador, H. El Lenguaje Integral y su caracterización en el Nivel Interactivo II. Comunicación personal. 2000.

Arellano, A. El lenguaje Integral: una alternativa para la educación. Venezuela: Editorial Venezolana. 1993.

Arguedas, R. Mapa semántico: una experiencia de aprendizaje con niños de II ciclo en una institución privada en la provincia de Heredia. Memoria Segundo Congreso de las Américas sobre 
Lectoescritura. (pp. 17-22). Costa Rica: Universidad Nacional. 1995.

Blanco, S. Asesoramiento a docentes del Nivel Interactivo II. Comunicación personal. 2000.

Bruner, E. El mapa semántico como estrategia para la integración curricular. Memoria Segundo Congreso de las Américas sobre Lectoescritura. (pp. 519-521). Costa Rica: Universidad Nacional. 1995.

Carretero, Mario. Introducción a la psicología cognitiva. Argentina: Aique. 1997.

Coll, C.; Martín, E.; Mauri, T.; Miras, M.; Onrubia, J.; Solé, I.; \& Zabala, A. El constructivismo en el aula. Barcelona, España: Editorial Graó. 1997.

Coto, C. El Lenguaje Integral y su caracterización en el Nivel Interactivo II. Comunicación personal. 2000.

Chaves, L. Cultura, escuela y apropiación de la lengua escrita. Documento sin publicar. 1999.

El Lenguaje Integral y su caracterización en el Nivel Interactivo II. Comunicación personal. 2000.

De la Torre, S., et al. Cómo innovar en los centros educativos. España: Editorial Escuela Española S. A. 1998.

Goodman, K. Lenguaje Integral. Mérida, Venezuela: Editorial Venezolana, C.A. 1989.
Goodman, K. El Lenguaje Integral como filosofía educativa. Primer Congreso de las Américas sobre Lectoescritura. (pp. 16-43). Venezuela. 1992.

Hernández, Omar. La etnografía y sus recursos básicos de investigación. Revista CIDE (s.f.).

Marchena, D. El Lenguaje Integral y su caracterización en el Nivel Interactivo II. Comunicación personal. 2000.

Murillo, M. Qué es la conversación formal o espontánea. Comunicación personal. 1999.

Picado, M. El Lenguaje Integral y su caracterización en el Nivel Interactivo II. Comunicación personal. 2000.

Rojas, P. Planeamiento didáctico elaborado para desarrollar la labor de aula. 1999.

Ruiz, D. La alfabetización temprana en el ambiente preescolar: nuevas perspectivas para aprender a leer y escribir. Puerto Rico. 1996.

Sáez, R.; López, L.; y Santiago, L. El Lenguaje Integral y la integración curricular: la experiencia del kindergarten puertorriqueño. Memoria Segundo Congreso de las Américas sobre Lectoescritura. (pp. 1643). Costa Rica: Universidad Nacional. 1995.

Salazar, E. El Lenguaje Integral y su caracterización en el Nivel Interactivo II. Comunicación personal. 2000.

Jeanneth Cerdas Núñez Docente, del Ministerio de Educación Pública

Ana Polanco Hernández Profesora de la Escuela de Formación Docente de la Universidad de Costa Rica Docente de Educación Preescolar del Miniserio de Educación Pública 
